\title{
Lo indecible de la privacidad contemporánea. Comentario a Carissa Véliz, Privacy is power: why and how you should take back control of your data
}

(2020) Bantam Press

London, 268 pp.

Carlos Fernández Barbudo

Universidad Internacional de la Rioja, Universidad Rey Juan Carlos

ORCID ID 0000-0003-0508-8032

carlos.fernandezbarbudo@unir.net

Cita recomendada:

Fernández Barbudo, C. (2019). Lo indecible de la privacidad contemporánea. Comentario a Carisa Véliz, Privacy is power: why and how you should take back control of your data. Eunomía. Revista en Cultura de la Legalidad, 21, pp. 427-430.

doi: https://doi.org/10.20318/eunomia.2021.6365

Recibido / received: 01/06/2018 Aceptado / accepted: 28/01/2019

Carissa Véliz, al final de su justamente exitoso libro «Privacy is Powen», nos confiesa una anécdota personal que encierra mucho más de lo que aparenta: «Six years ago, when I told people I was researching privacy, the most common response I got was bleak and cynical. "Oh, so you're doing history, not philosophy". "Privacy is dead. Get used to it. Nothing to think about"». En aquellos momentos yo comenzaba mi tesis doctoral en España sobre el mismo tema y las respuestas que recibía estaban más ligadas a una confusión terminológica - ¿ ¿privacidad? querrás decir intimidad, ¿no?». Hoy, sin embargo, casi cualquier persona entiende intuitivamente la cuestión de la privacidad y la relaciona, justamente, con el subtítulo de la obra de Véliz, «take back control of your data». De ahí que cuando se publique la versión en español de esta obra no habrá dudas a la hora de cómo traducir este concepto, situación que hubiera sido distinta hace pocos años como ocurrió en 1995 cuando el Centro de Estudios Políticos y Constitucionales tradujo la célebre obra de Warren y Brandeis «The Right to Privacy» como «El derecho a la intimidad» 1.

\footnotetext{
${ }^{1}$ En la introducción Benigno Pendás afirma rotundamente que el término privacidad es un anglicismo y que es preferible traducir privacy como vida privada o intimidad.
} 
El hecho de que en España se haya popularizado el término privacidad cuando en otros ambientes intelectuales se la daba por muerta fue lo que me llevó a titular un artículo de opinión que se publicó en la revista ctxt del siguiente modo: "La necesaria muerte de la privacidad». La recepción de los debates anglosajones sobre los riesgos que la vida digital suponen a la intimidad personal hizo que se escindieran dos ámbitos semánticos antes reunidos. Si llegó como un anglicismo es lo de menos, lo relevante es que el concepto de privacidad recogió una experiencia colectiva que es la que narra Véliz en su obra y lo que me llevó a defender que hemos presenciado el surgimiento de un nuevo concepto político (véase, Barbudo, 2019). Sin su muerte, no hubiésemos asistido a su nacimiento.

Entonces, ¿en qué consiste este nuevo concepto de privacidad? Y quizá lo más importante, ¿por qué Véliz afirma que la privacidad es poder? Al lector quizá le sorprenda que la autora no proporcione una definición de privacidad, sin embargo, esto no quiere decir que no encontremos en la obra una concepción coherente de en qué consiste la misma. De hecho, esta situación es bastante habitual en las discusiones, tanto intelectuales como sociales, sobre este tema y esto es debido a que la privacidad es un concepto reactivo. Rara vez vamos a encontrar una definición positiva que delimite el alcance de la misma. Lo habitual es justamente lo contrario, es decir, emplear este concepto para dar cuenta de una nueva situación habitualmente relacionada con la tecnología- que se concibe como una amenaza. Solo cuando aparece la amenaza, ese «algo» que debe ser objeto de protección se hace presente, ya que antes que pensarse como un bien social en términos positivos, la privacidad solo parece poder plantearse en términos negativos: por rechazo a lo que acontece.

El hecho de que la privacidad parezca que solo se puede pensar a través de los límites que se establecen frente a lo que se consideran injerencias, se aprecia con claridad en la obra de Véliz. La ausencia de una definición explícita de este concepto es suplida mediante esta estrategia reactiva. De este modo, la autora nos plantea a lo largo del libro un amplio abanico de tecnologías y fenómenos sociotécnicos, todos ellos derivados de la economía de la vigilancia, que suponen una amenaza directa o indirecta a la privacidad. Ahora bien, si esto fuera netamente así, cualquier cosa podría considerarse una amenaza para algo que no es nada concreto, de ahí que sí que exista un hilo conductor entre todas estas amenazas: la limitación de la autonomía personal.

De este modo, el trabajo de Véliz forma parte de la larga tradición liberal que identifica el ámbito íntimo con el espacio social en el que el individuo goza de máxima autonomía. Para esta tradición, el hogar es el máximo exponente de la autodeterminación individual y los muros de la casa conforman la principal barrera de defensa frente al mundo social. No en vano la metáfora por excelencia para explicar en qué consiste la intimidad recurre a las cuatro paredes de la casa, ya que todo lo que ocurre en su interior no incumbe a nadie y debe ser protegido del juicio social levantando unas paredes jurídicas que lo defiendan de las injerencias externas. Sin intimidad, no hay libertad.

El problema actual es que las paredes de la casa ya no bastan para proteger esa intimidad. Ahora somos ciborgs cuyas vidas están embebidas en redes de datos, lo cual supone que los aspectos más íntimos de nuestros yoes estén depositados mucho más allá de nuestro hogar. Esta situación, aunque nos parezca muy novedosa, ha sido siempre bien conocida. Las primeras legislaciones en materia de protección de datos personales surgen cuando la interconexión global de datos estaba aún en sus primeras fases, pero ya se advertía que las bases de datos suponían una amenaza a la intimidad, por lo que se decidió dar a los individuos cierta capacidad de 
decisión sobre la información que se almacena remotamente sobre ellos. Esta dimensión informacional de la intimidad se tematizó en la literatura especializada como informational privacy, que es justamente la privacidad de la que nos habla Véliz en su trabajo.

Esta tradición, cuando se adapta a las nuevas circunstancias informacionales de la privacidad, rearticula los conceptos adyacentes a la privacidad y coloca la confidencialidad en una posición central. Desde el momento en que la información sobre uno ya no está bajo el control directo del individuo, lo que urge organizar para salvaguardar la intimidad en el ámbito digital son mecanismos que garanticen que solo las personas autorizadas puedan acceder a dicha información, o lo que es lo mismo: garantizar su confidencialidad. De este modo, las nuevas paredes de la casa son las tecnologías que impiden que personas no legitimadas tengan esa capacidad de acceso y se desarrolla desde el campo técnico -el de la seguridad de la información- el paradigma CIA que aún hoy es dominante: Confidentiality, Integrity y Availability $^{2}$.

Ahora bien, bajo condiciones capitalistas de producción los datos -ya sean personales o no- se ven sometidos a las mismas dinámicas de acumulación que cualquier otra mercancía, de ahí que se desarrolle una economía de la vigilancia orientada a la extracción de información sobre los individuos. Esto hace que cambie la escala del problema, pues la amenaza ya no son bases de datos de alcance limitado, sino gigantescos centros de datos en los que se almacenan nuestros yoes digitales. $Y$ con ello se produce, desde hace pocos años, una eclosión intelectual que trata de revisitar la cuestión inicial de la autonomía individual.

Muchos autores comienzan a darse cuenta de que el papel central que la confidencialidad tenía en la informational privacy ya no permite responder adecuadamente a este cambio de escala, pues lo determinante para las nuevas cuestiones que se abren no es quién accede a la información sino qué hace con ella. Ahí es donde se nos presenta claramente la cuestión del poder en relación con la acumulación de datos. La obra de Véliz propone encauzar este nuevo debate desde una concepción del poder muy restringida pero adecuada para los fines del trabajo. Entender el poder como capacidad de influir en los comportamientos le permite a la autora centrar el debate entre privacidad y economía de la vigilancia, y plantear con claridad lo específico de la actual acumulación de datos, a saber: que permite alcanzar un conocimiento tan detallado sobre los individuos que se habilitan nuevos mecanismos de manipulación de masas. De este modo, Véliz está hablando de «algo» que va más allá de la dimensión informacional, e incluso de la misma privacidad.

Ese más allá está siendo planteado actualmente a través de la idea de privacidad colectiva y ahí es donde se revela lo indecible de la privacidad contemporánea, ya que tanto la privacidad como la intimidad siempre se han comprendido como una cuestión relativa al individuo. Entonces, ¿cómo puede ser algo colectivo? Una cosa es afirmar que la privacidad es un bien social que se disfruta individualmente y que las instituciones que protegen este ámbito privado son colectivas, como recoge Véliz, y otra muy distinta defender que existe una dimensión contemporánea de la privacidad que es, en sí misma, colectiva, como algunos autores estamos tratando de explorar (véase, Barbudo, 2020). Lo indecible de la privacidad estaría, precisamente, en ese ámbito semántico que se resiste a morir y que no

\footnotetext{
2 En este contexto, la confidencialidad es un conjunto de reglas que limita el acceso a la información, la integridad es la garantía de que la información es confiable y veraz, y la disponibilidad es una garantía de acceso confiable a la información por parte de personas autorizadas.
} 
termina de nacer conceptualmente. Ahí está, a mi juicio, el límite de la obra de Véliz: sigue enmarcada en un paradigma individualista de la privacidad desde el que es muy difícil apreciar en qué sentido existe una privacidad que ya no tiene, porque tampoco lo tienen las tecnologías de vigilancia, al individuo en su centro. Solo desde una perspectiva posindividual es posible dar ese salto, aunque esto supone desligar completamente la privacidad de la intimidad, cosa que no es fácil debido al bagaje jurídico-político que arrastramos y que parece renovarse contemporáneamente como derecho a la privacidad (electrónica).

Solo desde un marco posindividual se podrá dar respuesta, tanto teórica como práctica, a los nuevos desafíos que la economía de la vigilancia ha traído consigo. Muchas de las cuestiones que plantea Véliz en su obra van justamente en esa dirección, pero quedan inarticuladas. El gran reto que tenemos por delante está, precisamente, en saber articular teóricamente lo que es ya una realidad sociotécnica. Estoy convencido de que los problemas relacionados con los sesgos en la Inteligencia Artificial, así como los nuevos campos de discriminación que se abren con esta tecnología, no pueden ser comprendidos completamente desde el paradigma individual que rige las teorías de la privacidad actual. El camino por recorrer apunta a repensar el campo de la autonomía política que está ligado a la privacidad desde un marco no individual, ya que desde esa hoja de ruta se podrá vislumbrar con mayor claridad cómo la vigilancia sistémica opera a la hora de influir en comportamiento colectivos y, por tanto, plantear las transformaciones sociotécnicas alumbradas por la economía de la vigilancia como una limitación de la soberanía digital de las comunidades políticas.

Si la privacidad es poder es porque la privacidad es política, y los cambios políticos no se producen desde la individualidad. Véliz finaliza su obra con un decidido optimismo orientado a empoderar a los ciudadanos: existen alternativas tecnológicas que respetan la privacidad, tenemos regulaciones que hacer valer y los consumidores pueden hacer presión para que la economía de la vigilancia deje de funcionar. Ahora bien, el problema de estas llamadas a la acción con las que finaliza el libro es que son todas ellas en clave individualista. Cuando precisamente lo que necesitamos es justamente lo contrario: socializar el malestar, hacerlo colectivo, y politizarlo.

\section{Bibliografía}

Fernández Barbudo, C. (2019). El nuevo concepto de privacidad: la transformación estructural de la visibilidad. Revista de Estudios Políticos, 185, pp. 139-167. doi: http://doi.org/10.18042/cepc/rep.185.05.

Fernández Barbudo, C. (2020). Hacia una privacidad colectiva: repensar las bases teóricas de la distinción público/privado en la economía de la vigilancia. Teknokultura. Revista de Cultura Digital y Movimientos Sociales, 17(1), pp. 6976. doi: http://doi.org/10.5209/tekn.66844. 